\title{
Corrigendum: Are Rich People Perceived as More Trustworthy? Perceived Socioeconomic Status Modulates Judgments of Trustworthiness and Trust Behavior Based on Facial Appearance
}

\section{OPEN ACCESS}

Approved by:

Frontiers Editorial Office, Frontiers Media SA, Switzerland

${ }^{*}$ Correspondence: Feng Du

duf@psych.ac.cn

Specialty section: This article was submitted to Personality and Social Psychology,

a section of the journal

Frontiers in Psychology

Received: 26 September 2019 Accepted: 27 September 2019

Published: 11 October 2019

Citation:

Qi Y, Li Q and Du F (2019) Corrigendum: Are Rich People Perceived as More Trustworthy? Perceived Socioeconomic Status

Modulates Judgments of Trustworthiness and Trust Behavior Based on Facial Appearance.

Front. Psychol. 10:2316. doi: 10.3389/fpsyg.2019.02316

\author{
Yue $Q i^{1,2}, Q i L^{1,2}$ and Feng $D u^{1,2 *}$ \\ ${ }^{1}$ CAS Key Laboratory of Behavioral Science, Institute of Psychology, Chinese Academy of Sciences, Beijing, China, \\ ${ }^{2}$ Department of Psychology, University of Chinese Academy of Sciences, Beijing, China
}

Keywords: socioeconomic status, facial judgment, trust, first impression, cooperation

\section{A Corrigendum on}

Are Rich People Perceived as More Trustworthy? Perceived Socioeconomic Status Modulates Judgments of Trustworthiness and Trust Behavior Based on Facial Appearance

by Qi, Y., Li, Q., and Du, F. (2018). Front. Psychol. 9:512. doi: 10.3389/fpsyg.2018.00512

There is an error in the Funding statement.

A correction has been made in the Funding statement:

"This research was supported by Beijing Natural Science Foundation (5184035); the National Natural Science Foundation of China (31470982, 31200782, and 31571161); the Scientific Foundation of the Institute of Psychology, Chinese Academy of Sciences (Y4CX033008); the Young Scientists Fund of the Institute of Psychology (Y5CX122005); and Magnetic Resonance Imaging Research Center, Institute of Psychology, CAS, and the China Scholarship Council."

The authors apologize for this error and state that this does not change the scientific conclusions of the article in any way. The original article has been updated.

Copyright (c) 2019 Qi, Li and Du. This is an open-access article distributed under the terms of the Creative Commons Attribution License (CC BY). The use, distribution or reproduction in other forums is permitted, provided the original author(s) and the copyright owner(s) are credited and that the original publication in this journal is cited, in accordance with accepted academic practice. No use, distribution or reproduction is permitted which does not comply with these terms. 